\title{
The interplay between movement, morphology and dispersal in Tetrahymena ciliates
}

\author{
Frank Pennekamp ${ }^{\text {Corresp., } 1,2}$, Jean Clobert $^{3}$, Jean Clobert , Nicolas Schtickzelle ${ }^{1}$ \\ ${ }^{1}$ Earth and Life Institute \& Biodiversity Research Centre, Université catholique de Louvain, Louvain-la-Neuve, Belgium \\ 2 Department of Evolutionary Biology and Environmental Studies, University of Zurich, Zurich, Switzerland \\ 3 Station d'Ecologie Théorique et Expérimentale, CNRS, Moulis, France \\ Corresponding Author: Frank Pennekamp \\ Email address: frank.pennekamp@ieu.uzh.ch
}

Understanding how and why individual movement translates into dispersal between populations is a long-term goal in ecology. Movement is broadly defined as "any change in the spatial location of an individual", whereas dispersal is more narrowly defined as a movement that may lead to gene flow. Because the former may create the condition for the latter, behavioural decisions that lead to dispersal may be detectable in underlying movement behaviour. In addition, dispersing individuals also have specific sets of morphological and behavioural traits that help them coping with the costs of movement and dispersal, and traits that mitigate costs should be under selection and evolve if they have a genetic basis. Here we experimentally study the relationships between movement behaviour, morphology and dispersal across 44 genotypes of the actively dispersing unicellular, aquatic model organism Tetrahymena thermophila. We used two-patch populations to quantify individual movement trajectories, as well as activity, morphology and dispersal rate. First, we studied variation in movement behaviour among and within genotypes (i.e. between dispersers and residents) and tested whether this variation can be explained by morphology. Then, we address how much the dispersal rate is driven by differences in the underlying movement behaviour. Genotypes revealed clear differences in terms of movement speed and linearity. We also detected marked movement differences between resident and dispersing individuals, mediated by the genotype. Movement variation was partly explained by morphological properties such as cell size and shape, with larger cells consistently showing higher movement speed and higher linearity. Genetic differences in activity and movement were positively related to the observed dispersal and jointly explained $47 \%$ of the variation in dispersal rate. Our study shows that a detailed understanding of the interplay between morphology, movement and dispersal may have potential to improve dispersal predictions over broader spatio-temporal scales. 
1 The interplay between movement, morphology and dispersal in Tetrahymena

2

3

4

5

6

7

8

9

10

11

12

13

14

15

16

17

18

19

20

21

22

23

24

25

26

\section{ciliates}

Frank Pennekamp ${ }^{1,2}$, Jean Clobert $^{3} \&$ Nicolas Schtickzelle $^{1}$

${ }^{1}$ Earth and Life Institute \& Biodiversity Research Centre, Université catholique de Louvain, Croix du Sud 4, L7.07.04, 1348 Louvain-la-Neuve, Belgium

${ }^{2}$ Present address: Department of Evolutionary Biology and Environmental Studies, University of Zurich, Winterthurerstrasse 190, 8057 Zurich, Switzerland ${ }^{3}$ Station d'Ecologie Théorique et Expérimentale, CNRS, 09200 Moulis, France

Running head: Movement ecology of Tetrahymena

Words: 6831(including references)

Address of corresponding author:

Frank Pennekamp

Department of Evolutionary Biology and Environmental Studies

University of Zurich

Winterthurerstrasse 190

CH-8057 Zurich

Switzerland

email: Frank.Pennekamp@ieu.uzh.ch

ORCID ID: https://orcid.org/0000-0003-0679-1045

\section{Code and data are available here:}

https://figshare.com/s/b7e4b795085dedec6204

https://figshare.com/s/54f792836833009ba70d

PeerJ reviewing PDF | (2018:02:24508:2:0:NEW 24 Oct 2019) 
27 Abstract

28 Understanding how and why individual movement translates into dispersal between populations

29 is a long-term goal in ecology. Movement is broadly defined as "any change in the spatial location

30 of an individual", whereas dispersal is more narrowly defined as a movement that may lead to gene

31 flow. Because the former may create the condition for the latter, behavioural decisions that lead to

32 dispersal may be detectable in underlying movement behaviour. In addition, dispersing individuals

33 also have specific sets of morphological and behavioural traits that help them coping with the costs

34 of movement and dispersal, and traits that mitigate costs should be under selection and evolve if

35 they have a genetic basis.

36 Here we experimentally study the relationships between movement behaviour, morphology and

37 dispersal across 44 genotypes of the actively dispersing unicellular, aquatic model organism

38 Tetrahymena thermophila. We used two-patch populations to quantify individual movement

39 trajectories, as well as activity, morphology and dispersal rate. First, we studied variation in

40 movement behaviour among and within genotypes (i.e. between dispersers and residents) and

41 tested whether this variation can be explained by morphology. Then, we address how much the

42 dispersal rate is driven by differences in the underlying movement behaviour.

43 Genotypes revealed clear differences in terms of movement speed and linearity. We also detected

44 marked movement differences between resident and dispersing individuals, mediated by the

45 genotype. Movement variation was partly explained by morphological properties such as cell size

46 and shape, with larger cells consistently showing higher movement speed and higher linearity.

47 Genetic differences in activity and movement were positively related to the observed dispersal and

48 jointly explained $47 \%$ of the variation in dispersal rate. Our study shows that a detailed

49 understanding of the interplay between morphology, movement and dispersal may have potential

50 to improve dispersal predictions over broader spatio-temporal scales. 


\section{Introduction}

52 Individual movement is a universal feature of life with broad implications for the ecology and

53 evolution of species (Turchin, 1998). As most environments are spatially structured, understanding

54 how individuals move across increasingly fragmented landscapes is of crucial importance

55 (Baguette \& Van Dyck, 2007). Individual movement can be defined as "any change in the spatial

56 location of an individual in time" (Nathan et al., 2008). Dispersal movements are more specifically

57 defined as the result of a specific movement type, i.e. movement that can potentially (but does not

58 necessarily) lead to gene flow (Baguette, Stevens \& Clobert, 2014) and are vital for the persistence

59 of spatially-structured populations. Although dispersal implies a change in spatial position, it goes

60 beyond mere movement: it is a central life history trait (Bonte \& Dahirel, 2017), which can be

61 conceptualized as a three stage process where decisions are taken during emigration, transition and

62 immigration (Clobert et al., 2009). Movement patterns may hence vary according to the costs of

63 dispersal (Bonte et al., 2012), for instance due to the type of habitat that is encountered

64 (Schtickzelle et al., 2007). Few studies try to integrate drivers of small-scale individual movements

65 with dispersal, although previous work has shown the potential of movement to predict large scale

66 spatial dynamics from short spatio-temporal scales, if variation in movement is properly accounted

67 for (Morales \& Ellner, 2002). This is important because dispersal has wide implications for

68 population dynamics and the spatial distribution of genetic diversity (Bowler \& Benton, 2005;

69 Ronce, 2007; Clobert et al., 2012; Jacob et al., 2015a).

70 Variation in movement and dispersal, and covariation with traits such as morphology and

71 behaviour, is the raw material for selection in spatially structured environments and can lead to

72 dispersal syndromes, i.e. consistent co-variation among traits (Ronce \& Clobert, 2012; Stevens et

73 al., 2012). Variation in both movement and dispersal has been reported within and among many 
74

different organisms (Austin, Bowen \& McMillan, 2004; Mancinelli, 2010; Chapperon \& Seuront, 2011; Ducatez et al., 2012; Debeffe et al., 2014; Dahirel et al., 2015). Some of this variation can be due to environmental causes (e.g. different resource availability, Fronhofer et al., 2018), but there is also evidence for genetic effects (Haag et al., 2005; Edelsparre et al., 2014). As only the latter can lead to the evolution of dispersal and movement strategies, it is important to understand when dispersal and movement variation is genetically or environmentally based. The development of new technology has recently given us a better grasp on how individual variation in movement is related to dispersal. Individual tracking of roe deer showed that exploratory movements were mainly performed by individuals that would later disperse (Debeffe et al., 2013, 2014), and butterflies show links between movement ability and dispersal (Stevens, Turlure \& Baguette, 2010). Currently, effects of proxies like body condition are very species and context-specific. However, movement traits have potential to more generally predict which individuals are most likely to disperse.

Besides movement, differences in morphology, physiology and behaviour have been found when comparing dispersers and residents (Niitepõld et al., 2009; Edelsparre et al., 2014). For instance, body condition and morphology have been found to influence individual dispersal decisions in mole rats, ciliates, lizards and butterflies and many other organisms (O'Riain, Jarvis \& Faulkes, 1996; Fjerdingstad et al., 2007; Clobert et al., 2009; Stevens et al., 2012; Turlure et al., 2016). Body size is another important predictor of movement, and has been shown to directly influence the speed with which animals can move (Hirt et al., 2017a,b). In general, larger animals can move faster, however, the relationship is non-linear with an optimum, suggesting that the largest species are not necessarily the fastest. 
96 Linking individual movement to dispersal requires us to characterize and understand the

97 underlying sources of variation in both, which has so far mostly be done on insects (Niitepõld et

98 al., 2009; Edelsparre et al., 2014). Assessing dispersal and movement simultaneously is difficult

99 because dispersal events (especially long-distance) are difficult to track in the field, and recording

100 movement behaviour with adequate resolution and sample size is technically challenging, leading

101 to the use of indirect methods (Flaherty, Ben-David \& Smith, 2010). Alternatively, relationships

102 between dispersal and movement ability have been studied across taxonomic groups in a

103 comparative fashion (Dahirel et al., 2015). One noteworthy exception using a direct approach is a

104 study that investigated and supported links between phenotypic and genotypic differences in larval

105 food foraging and dispersal as adults in Drosophila melanogaster (Edelsparre et al., 2014).

106 "Rover" larvae tend to move longer distances and may leave food patches when foraging, whereas

107 "sitters" tend to move less and rest within their food patch (Osborne et al., 1997). In dispersal

108 assays the "rover" genotype also moved greater distances as adult flies, highlighting genetic links

109 between larval mobility and adult dispersal (Edelsparre et al., 2014). Experiments with

110 microscopic organisms are ideal to study the connections between dispersal and movement

111 experimentally, because they allow tight control of the genetic and environmental context and

112 hence allow these to be disentangled.

113 Experimental approaches with microscopic organisms are a convenient way to measure movement

114 and dispersal simultaneously and hence allow us to study pattern and process at a relevant spatial

115 scale (Menden-Deuer, 2010; Kuefler, Avgar \& Fryxell, 2012). Moreover, controlled experiments

116 can partition how much variation in movement is due to genetic and non-genetic sources and

117 therefore advance our understanding of the mechanistic underpinnings of movement strategies and 
118 their evolution. In this study, we used the microbial Tetrahymena thermophila experimental 119 system.

120 There is compelling evidence that dispersal in this organism is not solely a diffusive process, but

121 depends on individual decisions triggered by environmental cues. Previous work has revealed that 122 cells modify their dispersal decisions according to cooperative strategies (Chaine et al., 2010; 123 Jacob et al., 2016), conspecific density and density proxies (Pennekamp et al., 2014; Fronhofer, 124 Kropf \& Altermatt, 2015), social information from conspecifics (Jacob et al., 2015b) as well as 125 competition (Fronhofer et al., 2015), and perform adaptive habitat choice according to thermal 126 preferences (Jacob et al., 2017, 2018). Extensive variation in dispersal has previously been 127 observed among genotypes of this actively moving ciliate, however, the underlying movement 128 processes have remained elusive.

129 Previous work has revealed extensive variation in life history traits among genotypes, including 130 trade-offs in general growth performance (including high dispersal ability) and formation of 131 specialized dispersal morphs (Fjerdingstad et al., 2007). Later work also revealed dispersal 132 plasticity regarding conspecific density, which could be partly explained by morphological 133 differences (body size and shape) among genotypes (Pennekamp et al., 2014)

134 In this study, we investigate the relationships between small-scale individual movement (i.e. cell 135 trajectories), dispersal (i.e. emigration rate) and morphological features (i.e. body size and shape) 136 across 44 genotypes of Tetrahymena thermophila. We characterized the movement behaviour of 137 in terms of activity (number of actively moving cells) and quantitative movement behaviour (speed 138 and the characteristic scale of autocorrelation) via video-based cell tracking (Pennekamp, 139 Schtickzelle \& Petchey, 2015). In addition, we measured morphological properties of each 
140 genotype, as well as its dispersal rate across the two-patch system. With this data, we addressed 141 the following questions:

142
1) Is there variation in movement behaviour within genotypes (between dispersers and residents) and among genotypes?

2) Can this movement variation be explained by morphology (cell size and shape)?

3) How much is the dispersal rate driven by differences in the underlying movement behaviour (activity and movement differences among genotypes)?

\section{Materials and Methods}

\section{Model organism}

Tetrahymena thermophila is a $30-50 \mu \mathrm{m}$ unicellular, ciliated protozoan inhabiting freshwater ponds and streams in the eastern part of North America, where it naturally feeds on patches of bacteria and dissolved nutrients (Doerder \& Brunk, 2012). We used a set of 44 genetically distinct genotypes (clonally reproducing as isolated lines) differing in several life history traits (Fjerdingstad et al., 2007; Schtickzelle et al., 2009; Chaine et al., 2010; Pennekamp et al., 2014). All genotypes are stored in suspended animation (frozen in liquid nitrogen) and can be ordered from the Tetrahymena Stock Center (https://tetrahymena.vet.cornell.edu/). Genotypes were kept as isolated monocultures in "common garden" conditions over a large number of generations (> 100) after defrosting, under axenic conditions in Proteose peptone medium enriched with yeast extract, at constant $27^{\circ} \mathrm{C}$ in a light controlled incubator with a $14: 10 \mathrm{~h}$ light/dark cycle both prior and during the experiment. Refer to the supplementary material (section 1) for additional information on these genotypes and details of culture conditions. 
161

162

163

164

165

166

167

168

169

170

171

172

173

174

175

176

177

178

179

180

181

182

\section{Experimental quantification of dispersal and movement parameters}

We quantified dispersal rate and movement parameters of $T$. thermophila cells using a fully factorial experimental design implying two factors of interest: the genotype (44 genotypes) and the dispersal status (dispersers vs residents). We used the same standardized two-patch system (subsequently referred to as dispersal system) developed in previous work (Fjerdingstad et al., 2007; Schtickzelle et al., 2009; Chaine et al., 2010; Pennekamp et al., 2014), consisting of two 1.5 $\mathrm{mL}$ microtubes connected by a silicon pipe (internal diameter $4 \mathrm{~mm}$, tube length $17 \mathrm{~mm}$ ), filled with medium (see supplementary material, Figure S1). To start the experiment, cells of a single genotype were pipetted into the "start" tube to obtain a density of 300000 cells $/ \mathrm{mL}$, an intermediate cell density commonly observed under our culturing conditions. After mixing the medium to distribute cells evenly in the start tube and 30 minutes of acclimation, the connecting pipe was opened, and cells could freely disperse. At the end of the experiment after six hours, the pipe was closed by a clamp and five independent samples were taken from both the start and the target tubes of each dispersal system. Cells found in the "start" or "target" are subsequently referred to "residents" or "dispersers", respectively, the two modalities possible for the dispersal status variable. Five dark field images (one for each chamber; resolution: 5616 x 3744 pixels) and one 40 s long video (of a randomly chosen chamber; HD resolution: 1920 x 1080 pixels; 25 frames per second) were then taken using a Canon EOS 5D Mark II mounted on a Nikon Eclipse 50i microscope with a $4 \mathrm{x}$ lens; the real size of the imaged area is about $6.3 \times 4.5 \mathrm{~mm}$ and was not bounded by external borders, hence cells could swim in and out the viewing field. Supplementary material (section 2) gives additional information about the experimental protocol and material used. 
183 Images were treated using an objective and automated image analysis workflow to count individual 184 cells and record morphology descriptors (cell size and cell shape); this workflow is based on 185 ImageJ (Schneider, Rasband \& Eliceiri, 2012) and was carefully validated and extensively 186 optimized to produce accurate and repeatable results (Pennekamp \& Schtickzelle, 2013).

187 Dispersal rate of a genotype was estimated as the ratio of density in the target tube to the overall 188 density (start + target), i.e. the proportion of cells in the target.

Individual cell trajectories were obtained from the digital videos in a standardized and automated fashion with a workflow that was later transformed into the R package BEMOVI (Pennekamp,

Schtickzelle \& Petchey, 2015) and was successfully used in previous studies extracting movement characteristics from video sequences (Banerji et al., 2015; Fronhofer, Kropf \& Altermatt, 2015; Griffiths et al., 2018). The position of each cell was followed over all the 1000 frames (40 s long video with 25 frames per second; Figure S2). First, the activity level of cells was computed from videos as the ratio of cells that moved (trajectory duration $>1$ s and minimum displacement $>50$ $\mu \mathrm{m}$, i.e. one body length) divided by the total number of trajectories (moving and non-moving).

Then, trajectories were analysed with continuous time movement models (Fleming et al., 2014;

198 Gurarie et al., 2017) to compute movement speed and linearity. Continuous time movement models are a natural choice for high-frequency sampling of video microscopy because they can deal with autocorrelation in the movement speed and positions. We used the smoove package in intuitive parameters such as movement speed and the velocity autocorrelation timescale (a measure

204 of the decay in directional persistence). For each genotype, we randomly subsampled 23 trajectories per replicate and tube resulting in a total of 6072 trajectories. The subsampling was 
206

207

208

209

210

211

212

213

214

215

216

217

218

219

220

221

222

223

224

225

226

227

228

necessary because analysis with continuous time movement models is computationally demanding due to the model selection procedure involved. Subsampling also ensured the same number of data points per genotype. For each trajectory, we fitted four models: an unbiased correlated velocity model (UCVM), an advective correlated velocity model (ACVM), a rotational correlated velocity model (RCVM) or a rotational advective correlated velocity model (RACVM). The best fitting model for a given trajectory was selected via a model selection procedure based on the Akaike information criterion (AIC), and parameters of the model estimated. For each trajectory, we extracted two parameters for further analysis: the movement speed (in root mean square) and the velocity autocorrelation timescale (parameter tau), essentially a measure of movement linearity. When tau tends towards zero, the movement approaches random Brownian motion, while tau tending towards infinity indicates perfect linear motion (Gurarie et al., 2017). We used the velocity likelihood fitting method rather than the exact fitting procedure implemented in Smoove, because Smoove currently supports the exact fitting approach for the UCVM model only. To check the robustness of the approximate fitting, we performed a check that indicated a negligible bias towards lower movement speed when using the approximate fitting (Figure S3). We therefore proceeded with the approximate fitting approach. Before further analysis, we performed an outlier exclusion based on the Median Absolute Deviation (MAD) with a threshold of 3 (Leys et al., 2013) for the two parameters estimated. The supplementary material (section 3) gives additional details concerning trajectory reconstruction from video, cleaning and estimation of movement metrics.

In summary, each dispersal system produced measures for six response variables: two morphology descriptors (cell size and shape, extracted from images), three movement descriptors (activity, speed, and linearity extracted from videos), and dispersal rate (computed from cell densities extracted from images). For all statistical analyses, these response variables were aggregated to 
229 produce two values per dispersal system, one for the start tube (residents) and another for the target

230 tube (dispersers); indeed, the true level of replication in this experiment was the dispersal system

231 (genotype $\mathrm{x}$ dispersal status combination) and not the individual trajectory. With 3 dispersal

232 systems (replicates) per genotype, sample size was 264 (44 genotypes * 3 replicates * 2 dispersal

233 status); note that one dispersal system (genotype 32_I) was discarded due to a technical failure of

234 the dispersal system, meaning $n=262$. Cell size and shape were averaged over all cells found on

235 the five images recorded per tube; activity was directly measured at the video level (1 measure per

236 tube) and hence already "pre-aggregated" at the correct level; speed and linearity were averaged

237 over the 23 trajectories analysed by continuous time movement models on each video; and

238 dispersal rate was computed from densities averaged over the five images recorded per tube.

\section{Statistical analyses}

240 To address our first question, activity and movement metrics (speed and linearity) were compared

241 among genotypes and among dispersal status (disperser vs resident cells) using a three-way

242 ANOVA, with genotype and dispersal status as crossed and fixed effects, and replicate as random

243 effect nested in genotype but crossed with dispersal status. Genotype was considered as a fixed

244 effect, despite its common consideration as a random effect (e.g. Crawley, 2007). This is because

245 the set of genotypes cannot be considered as a random sample of the genetic variation exhibited

246 by the species in the wild (some genotypes were selected due to previous results or based on their

247 phenotypic characteristics, some others were created by inbreeding in the laboratory). Dispersal

248 status was crossed with replicate because the data for the two statuses (disperser and resident, i.e.

249 target and start tubes respectively) were paired for each dispersal two-patch system. Speed and

250 linearity (tau) were $\ln$-transformed to improve normality. 
251 All cells belonging to the same genotype should have the same genetic make-up; however,

252 environmental differences encountered during the cell life cycle may lead to different

253 morphologies and cell states. Therefore, to answer our second question, we tested whether

254 differences in movement behaviour between residents and dispersers may be explained by

255 morphological differences such as cell size and shape. To see if there were differences between

256 residents and dispersers, we built ANCOVA models that related movement speed and linearity to

257 morphology properties (size and shape) across genotypes, accounting for differences due to

258 dispersal status. As some of the observed variation may be due to variation across replicates, we

259 investigated how within replicate differences in morphology affect differences in movement. We

260 used the Akaike Information criterion (AIC) to determine the most parsimonious model, i.e. the

261 simplest model (in terms of number of parameters) within 2 units (deltaAIC $<2$ ) of the best model

262 (i.e. with the lowest AIC).

263 To address our third question about the power of movement behaviour to predict dispersal rate, we

264 assessed how much variation in dispersal rate was explained by genotype-specific activity, 265 movement speed, movement linearity and all predictors together. We used the $\mathrm{R}^{2}$ of a multiple 266 regression and compared the three models with the Akaike Information criterion (AIC) to find the 267 best fitting model. For this analysis, movement metrics (activity, movement speed and linearity) 268 were averaged at the genotype level, i.e. over dispersers and residents.

\section{Results}

\section{Q1: variation in movement behaviour within and among genotypes}

271 Model selection across the four types of correlated velocity models revealed that the advective

272 correlated velocity model (ACVM) was the most common across genotypes, indicating the 
273 genotypes show directed movement. The dispersal status did not change the overall pattern, but

274 genotypes showed variation in the relative frequencies of movement models (Figure 1). Genotypes

275 differed in activity (min. $39 \%$ to max. $70 \%$ of total cell population moving) and movement

276 parameters extracted from the correlated velocity models: movement speed (min. 75 to max. 289

$277 \mu \mathrm{m} / \mathrm{s}$ ) and linearity (tau: min. 0.039 to max. 0.13). Additionally, a highly significant difference

278 was shown between dispersal status: compared to residents, dispersers were characterized by a

279 higher activity $(0.62+/-0.05$ vs. $0.57+/-0.08)$ and faster and more linear movements (speed +/-

280 SD: $171+/-52.5 \mu \mathrm{m} / \mathrm{s}$ vs. $139+/-52.0$; tau: $0.0804+/-0.0271$ vs. $0.0602+/-0.0244)$. For the

281 majority of genotypes the dispersers moved faster and more linear, while for some genotypes the

282 opposite was observed (significant genotype $\mathrm{x}$ dispersal status interaction for both movement

283 metrics; Table 1, Figure 2). Across genotypes the speed and linearity strongly positively co-varied

$284(b=0.000383, t=10.961, p<0.001)$, meaning faster cells also swam straighter. Neither intercept

285 nor slope differed between residents and dispersers (Figure S4).

286 Q2: link between movement behaviour and morphology

287 First, the influence of cell morphology on cell movement across genotypes and replicates was

288 analysed (Figure 3). The most parsimonious model indicated a positive effect of size on movement

289 speed in addition to the higher speed generally found in dispersers (Tab. S2). Speed was also

290 affected by shape differences: more elongated disperser cells moved faster, whereas the opposite

291 was observed for residents (Tab. S2). We also found that larger cells moved straighter. The slope

292 of this relationship did not differ among dispersal status, however, dispersers moved straighter on

293 average (Tab. S3). The relationship between shape and linearity again was dependent on the

294 dispersal status: whereas higher elongation led to more linear movement for dispersers, residents

295 showed no pattern with higher elongation (Tab. S3). Within genotypes, larger relative size of 
296 dispersers compared to residents led to higher relative movement speed, whereas a larger relative

297 elongation resulted in a decrease in relative speed (Figure S5, Tab. S4-S5).

298

299

300

301

302

303

304

305

306

307

308

309

310

311

312

313

314

315

316

317

\section{Q3: predicting dispersal rate based on movement parameters}

Consistent with previous experiments, we observed major differences among genotypes in dispersal rate in the two-patch experiment (Figure 4). The genotypes had significantly different dispersal rates over $6 \mathrm{~h}$ (one-way ANOVA: $\mathrm{F}_{43,87}=9.93, \mathrm{p}<0.001$ ), continuously distributed in the $7-71 \%$ range; the majority of genotypes had a dispersal rate lower than $50 \%$. Variation among the 44 genotypes in activity and movement behaviour explained a substantial amount of the variation observed in their dispersal rates. Only considering activity explained $27 \%$ of the variation in dispersal rates among genotypes $(\mathrm{AIC}=-56.21)$. The genotype-specific movement linearity explained a lower amount of variation $(24 \%$, AIC $=-54.55)$ while speed explained a larger percentage of the dispersal variation $(37 \%, \mathrm{AIC}=-62.86)$. Including activity, speed and linearity explained almost $50 \%$ of the variation in dispersal $(47 \%, \mathrm{AIC}=-66.79)$. This result indicates that activity and movement features jointly influence the dispersal rate exhibited by a genotype and provide complementary information about dispersal.

\section{Discussion}

We show that 44 genotypes of Tetrahymena thermophila kept in "common garden" conditions over many generations exhibit continuous variation in movement parameters (activity, movement speed and linearity). Activity, movement speed and linearity were found to be genotypedependent, and differed with dispersal status. Although cells within the same genotype have the same genetic make-up, environmental differences encountered during the cell life cycle may lead to different movement behaviours. We show that some of the movement variation can indeed be 
318 explained by morphological differences among genotypes and this may explain also within 319 genotype variation. Finally, movement variation and cell activity was highly predictive of 320 dispersal, explaining $47 \%$ of the observed variation.

\section{Genotype-based movement behaviour differences}

322 So far there are a limited number of model systems where the genetic basis of dispersal has been

323 studied in detail (summarized by Wheat, 2012). In Drosophila, allelic variation in the candidate

324 gene for is known to influence the foraging behaviour of larvae; additionally recent research has

325 demonstrated that phenotypic and genotypic variation mainly due to the for gene also influences

326 adult dispersal distances (Edelsparre et al., 2014). Interestingly, the protein encoded by the for

327 gene in Drosophila, a cGMP-dependent protein kinase, responsible for the observed behavioural

328 variation in foraging, is also known to influence cilia-mediated chemotaxis in T. thermophila

329 (Leick \& Chen, 2004). Another example is the nematode Caenorhabditis elegans where the npr1

330 gene is associated with both foraging strategy and dispersal behaviour (Gloria-Soria \& Azevedo,

331 2008). Finally, dispersal is heritable in the butterfly Melitaea cinxia on the Aland archipelago:

332 young and isolated populations have higher frequencies of dispersive female individuals carrying

333 the PGI genotype, a genotype associated with higher flight metabolic rate that increases the 334 probability to reach such habitats (Haag et al., 2005). These examples show that genetic links 335 between movement and dispersal exist and are consistent with our results, where movement over 336 short spatio-temporal scales correlates with dispersal over much larger spatio-temporal scales. $T$.

337 thermophila may be a good model species for studying these questions using experimental 338 evolution approaches. Promising directions for future research would be to understand how 339 different selection pressures for movement (within patches) and dispersal (among patches) interact 340 and affect eco-evolutionary dynamics in metapopulations (Van Petegem et al., 2015; Jacob et al., 
$3412015 \mathrm{a}, 2017,2018$ ) and during range expansions (Fronhofer \& Altermatt, 2015), contributing to a

342 broader understanding of spatial patterns in ecology.

343 Movement differences between dispersers and residents, and their relationship with

344 morphology

345 We have found significant variation in movement within genotypes, which was modulated by the

346 genotype (significant genotype by dispersal status interaction): disperser cells within the same

347 genotype moved faster and straighter than residents, suggesting different movement strategies,

348 which were realized to different degrees by different genotypes. These differences are partly

349 explained by cell morphology co-varying with movement. This is expected, as the energetic costs

350 of movement of microscopic organisms in aquatic environments are heavily influenced by their

351 morphology such as cell elongation and size (Mitchell, 2002; Young, 2007). Indeed, we found that

352 larger cells moved faster, regardless of their dispersal status. The shape of the cells also influenced

353 speed and linearity: dispersing cells that were more elongated moved faster and more linear,

354 whereas resident cells did not show such a relationship. The differences in movement speed are

355 likely due to different costs associated with motion in the liquid medium, with larger cells

356 potentially having larger energy reserves and/or stronger movement machinery (Mitchell, 2002).

357 This is corroborated by the fact that size always favoured faster movement, even when accounting

358 for the genotype effect (see Figure S4). Our results therefore closely agree with recent findings

359 about a general allometric relationship between body size and movement speed (Hirt et al., $3602017 \mathrm{a}, \mathrm{b})$.

361 We have shown that movement variation can be partly explained by different cell sizes and shapes.

362 This is in line with previous findings on the condition dependence of dispersal that indicated that

363 cell size and shape have an influence on the dispersal propensity (Pennekamp et al., 2014). 
364 However, in contrast to dispersal, larger and more elongated cells move faster and straighter, 365 whereas more elongated and smaller cells disperse more. This contrasting result suggests that 366 although larger cells may be superior in terms of movement ability, they may not disperse as much

367 as expected as other causes of dispersal may be more important; for instance, dispersal decisions

368 may be taken as a function of competitive ability rather than movement ability per se (Fronhofer 369 et al., 2015). If cell size positively co-varies with competitive ability, smaller cells may disperse 370 to escape the local competition although they have relatively weaker movement capabilities.

371 Aggregation behaviour of $T$. thermophila ciliates is another candidate for explaining movement 372 differences because aggregation affects the spatial cohesion of a population and is a proxy for 373 cooperative behaviour (Schtickzelle et al., 2009; Chaine et al., 2010; Jacob et al., 2015b). In a 374 previous study, genotypes characterized by different degrees of aggregation did not show any 375 relationship with dispersal (Schtickzelle et al., 2009). Instead aggregation co-varied with the occurrence of specialized dispersal morphs, which only appear during prolonged periods of starvation. Given the strong correlation we found between dispersal and movement, aggregation seems less likely to be a causal driver of the observed differences in movement, albeit information about cooperative strategies was found to influence dispersal decisions (Jacob et al., 2015b).

\section{Explaining dispersal rate with activity and movement variation}

The amount of variation explained increased from $27 \%$ accounting only for genotype-specific cell activity level, to $37 \%$ when considering only genotype-specific movement speed, and up to $47 \%$ when considering genotype-specific activity and movement. Activity and movement hence provide complementary information about dispersal. For instance, in certain genotypes, individual cells may move faster and straighter, but their activity level may be lower, compared to a less mobile genotype were cells are generally more active. The increasing amount of variation 
387 explained in our study supports the claim of previous studies that behavioural differences are

388 important for the correct prediction of large scale population distributions from small scale

389 movement observations (Morales \& Ellner, 2002; Newlands, Lutcavage \& Pitcher, 2004).

390 However, our results also indicate that other processes, including subtle behavioural differences

391 among genotypes to enter narrow tubes, may contribute to the observed variation in dispersal. As

392 the causes of movement and dispersal are not entirely known for each genotype in our study, both

393 positive and negative influence on the genetic variation are plausible as one cause (e.g. density of

394 conspecifics) may be more important for some genotypes than for others (Pennekamp et al., 2014).

What are the consequences of the geno- and phenotypic variation in movement 396 behaviour observed in our study?

397 Natural populations of Tetrahymena thermophila ciliates are often constituted of multiple 398 genotypes (Doerder et al., 1995), which may differ in movement behaviour as shown here.

Modelling work has shown that communities/populations consisting of multiple phenotypes can 400 actually show faster invasion speeds than that of the fastest monomorphic population alone (Elliott \& Cornell, 2012). This was, however, only the case if the two phenotypes, i.e. a resident and a dispersive type, showed co-variation between growth rate and dispersal ability (e.g. well growing between genotypes in these parameters varied two- to ten-fold. Looking at the variation of our genotypes (Figure 4), we see that the ratio in dispersal rate can be up to ten-fold depending on the genotypes contrasted. This suggests that with a known variation in growth rate with a factor of 407 about two (Pennekamp, 2014), accelerating invasions of Tetrahymena are possible, if natural 408 populations are more phenotypically diverse. Validating these predictions in experiments with 
409 mixed populations and their link with local adaptation would be a fruitful avenue for future 410 research.

\section{Conclusions}

412 Our study showed a close link between movement and dispersal on multiple levels. Dispersal 413 predictions steadily improved when genotype differences in both activity level and movement 414 behaviour were considered. This highlights that predictions of dispersal will benefit from a detailed 415 understanding of the underlying movement behaviour. To move beyond short-term ecological 416 predictions of dispersal dynamics, e.g. range expansions and range shifts due to environmental 417 change, we would need to further improve our understanding of how movement is affected by 418 environmental variation and the relative fitness prospects of cells if staying in their current habitat 419 patch or emigrating to another patch, which can lead to habitat choice, which has been shown in 420 the species linked to temperature (Jacob et al., 2017, 2018).

\section{Acknowledgments}

422 Virginie Thuillier and Linda Dhondt provided valuable help during the experiment and data 423 collection. F. P. Doerder kindly provided a collection of 22 wild type genetic lines of $T$. 424 thermophila. We thank Delphine Legrand, Emanuel Fronhofer, Staffan Jacob, Camille Turlure, 425 Justin Calabrese and anonymous reviewers for providing valuable comments on earlier drafts of 426 the manuscript. This is publication BRCXXX of the Biodiversity Research Centre. 


\section{References}

429 Austin D, Bowen WD, McMillan JI. 2004. Intraspecific variation in movement patterns: modeling 430 individual behaviour in a large marine predator. Oikos 105:15-30. DOI: 10.1111/j.0030-

431 1299.1999.12730.x.

432

Baguette M, Stevens VM, Clobert J. 2014. The pros and cons of applying the movement ecology paradigm for studying animal dispersal. Movement Ecology 2:13. DOI: 10.1186/s40462-0140013-6.

Baguette M, Van Dyck H. 2007. Landscape connectivity and animal behavior: functional grain as a key determinant for dispersal. Landscape Ecology 22:1117-1129.

Banerji A, Duncan AB, Griffin JS, Humphries S, Petchey OL, Kaltz O. 2015. Density- and trait-mediated effects of a parasite and a predator in a tri-trophic food web. Journal of Animal Ecology 84:723733. DOI: $10.1111 / 1365-2656.12317$.

Bonte D, Dahirel M. 2017. Dispersal: a central and independent trait in life history. Oikos 126:472-479.

DOI: 10.1111/oik.03801.

Bonte D, Dyck HV, Bullock JM, Coulon A, Delgado M, Gibbs M, Lehouck V, Matthysen E, Mustin K, Saastamoinen M, Schtickzelle N, Stevens VM, Vandewoestijne S, Baguette M, Barton K, Benton

Bowler DE, Benton TG. 2005. Causes and consequences of animal dispersal strategies: relating individual TG, Chaput-Bardy A, Clobert J, Dytham C, Hovestadt T, Meier CM, Palmer SCF, Turlure C, Travis JMJ. 2012. Costs of dispersal. Biological Reviews 87:290-312. DOI: 10.1111/j.1469behaviour to spatial dynamics. Biological Reviews 80:205-225.

Chaine AS, Schtickzelle N, Polard T, Huet M, Clobert J. 2010. Kin-based recognition and social aggregation in a ciliate. Evolution 64:1290-1300. 
451 Chapperon C, Seuront L. 2011. Variability in the motion behaviour of intertidal gastropods: ecological

452 and evolutionary perspectives. Journal of the Marine Biological Association of the United $453 \quad$ Kingdom 91:237-244.

454 Clobert J, Baguette M, Benton TG, Bullock JM. 2012. Dispersal Ecology and Evolution. Oxford University $455 \quad$ Press.

456 Clobert J, Le Galliard JF, Cote J, Meylan S, Massot M. 2009. Informed dispersal, heterogeneity in animal

457

458

459

460

461

462

463

464

465

466

467

468

469

470

471

472

473

474 dispersal syndromes and the dynamics of spatially structured populations. Ecology Letters 12:197-209.

Crawley MJ. 2007. The R Book. John Wiley \& Sons.

Dahirel M, Olivier E, Guiller A, Martin M-C, Madec L, Ansart A. 2015. Movement propensity and ability correlate with ecological specialization in European land snails: comparative analysis of a dispersal syndrome. Journal of Animal Ecology 84:228-238. DOI: 10.1111/1365-2656.12276.

Debeffe L, Morellet N, Bonnot N, Gaillard JM, Cargnelutti B, Verheyden-Tixier H, Vanpé C, Coulon A, Clobert J, Bon R, Hewison AJM. 2014. The link between behavioural type and natal dispersal propensity reveals a dispersal syndrome in a large herbivore. Proceedings of the Royal Society of London B: Biological Sciences 281:20140873. DOI: 10.1098/rspb.2014.0873.

Debeffe L, Morellet N, Cargnelutti B, Lourtet B, Coulon A, Gaillard JM, Bon R, Hewison AJM. 2013. Exploration as a key component of natal dispersal: dispersers explore more than philopatric individuals in roe deer. Animal Behaviour 86:143-151. DOI: 10.1016/j.anbehav.2013.05.005.

Doerder FP, Brunk C. 2012. Natural populations and inbred strains of Tetrahymena. In: Kathleen Collins ed. Tetrahymena thermophila. Methods in Cell Biology. Academic Press, 277-300.

Doerder FP, Gates MA, Eberhardt FP, Arslanyolu M. 1995. High frequency of sex and equal frequencies of mating types in natural populations of the ciliate Tetrahymena thermophila. Proceedings of the National Academy of Sciences of the United States of America 92:8715-8718. 
475

476

477

478

479

480

481

482

483

484

485

486

487

488

489

490

491

492

493

494

495

496

497

498

Ducatez S, Legrand D, Chaput-Bardy A, Stevens VM, Freville H, Baguette M. 2012. Inter-individual variation in movement: is there a mobility syndrome in the large white butterfly Pieris brassicae? Ecological Entomology 37:377-385.

Edelsparre AH, Vesterberg A, Lim JH, Anwari M, Fitzpatrick MJ. 2014. Alleles underlying larval foraging behaviour influence adult dispersal in nature. Ecology Letters 17:333-339. DOI: 10.1111/ele.12234.

Elliott EC, Cornell SJ. 2012. Dispersal Polymorphism and the Speed of Biological Invasions. PLoS ONE 7:e40496. DOI: 10.1371/journal.pone.0040496.

Fjerdingstad EJ, Schtickzelle N, Manhes P, Gutierrez A, Clobert J. 2007. Evolution of dispersal and life history strategies - Tetrahymena ciliates. BMC Evolutionary Biology 7:133. DOI: 10.1186/14712148-7-133.

Flaherty EA, Ben-David M, Smith WP. 2010. Diet and food availability: implications for foraging and dispersal of Prince of Wales northern flying squirrels across managed landscapes. Journal of Mammalogy 91:79-91. DOI: 10.1644/09-MAMM-A-014R.1.

Fleming $\mathrm{CH}$, Calabrese JM, Mueller T, Olson KA, Leimgruber P, Fagan WF. 2014. From Fine-Scale Foraging to Home Ranges: A Semivariance Approach to Identifying Movement Modes across Spatiotemporal Scales. The American Naturalist 183:E154-E167. DOI: 10.1086/675504.

Fronhofer EA, Altermatt F. 2015. Eco-evolutionary feedbacks during experimental range expansions. Nature Communications 6:6844. DOI: 10.1038/ncomms7844.

Fronhofer EA, Klecka J, Melián CJ, Altermatt F. 2015. Condition-dependent movement and dispersal in experimental metacommunities. Ecology Letters 18:954-963. DOI: 10.1111/ele.12475.

Fronhofer EA, Kropf T, Altermatt F. 2015. Density-dependent movement and the consequences of the Allee effect in the model organism Tetrahymena. Journal of Animal Ecology 84:712-722. DOI: 10.1111/1365-2656.12315. 
499 Fronhofer EA, Legrand D, Altermatt F, Ansart A, Blanchet S, Bonte D, Chaine A, Dahirel M, Laender FD, 500 Raedt JD, Gesu L di, Jacob S, Kaltz O, Laurent E, Little CJ, Madec L, Manzi F, Masier S, Pellerin F, 501 Pennekamp F, Schtickzelle N, Therry L, Vong A, Winandy L, Cote J. 2018. Bottom-up and top-

502

503

504

505

506

507

508

509

510

511

512

513

514

515

516

517

518

519

520

521 down control of dispersal across major organismal groups. Nature Ecology \& Evolution 2:1859. DOI: $10.1038 / s 41559-018-0686-0$.

Gloria-Soria A, Azevedo RBR. 2008. npr-1 regulates foraging and dispersal strategies in Caenorhabditis elegans. Current Biology 18:1694-1699.

Griffiths JI, Petchey OL, Pennekamp F, Childs DZ. 2018. Linking intraspecific trait variation to community abundance dynamics improves ecological predictability by revealing a growth-defence tradeoff. Functional Ecology 32:496-508. DOI: 10.1111/1365-2435.12997.

Gurarie E, Fleming CH, Fagan WF, Laidre KL, Hernández-Pliego J, Ovaskainen O. 2017. Correlated velocity models as a fundamental unit of animal movement: synthesis and applications. Movement Ecology 5:13. DOI: 10.1186/s40462-017-0103-3.

Haag CR, Saastamoinen M, Marden JH, Hanski I. 2005. A candidate locus for variation in dispersal rate in a butterfly metapopulation. Proceedings of the Royal Society B: Biological Sciences 272:24492456.

Hirt MR, Jetz W, Rall BC, Brose U. 2017a. A general scaling law reveals why the largest animals are not the fastest. Nature Ecology \& Evolution 1:1116. DOI: 10.1038/s41559-017-0241-4.

Hirt MR, Lauermann T, Brose U, Noldus LPJJ, Dell Al. 2017b. The little things that run: a general scaling of invertebrate exploratory speed with body mass. Ecology 98:2751-2757. DOI: 10.1002/ecy.2006.

Jacob S, Bestion E, Legrand D, Clobert J, Cote J. 2015a. Habitat matching and spatial heterogeneity of phenotypes: implications for metapopulation and metacommunity functioning. Evolutionary Ecology 29:851-871. DOI: 10.1007/s10682-015-9776-5. 
522 Jacob S, Chaine AS, Schtickzelle N, Huet M, Clobert J. 2015b. Social information from immigrants:

523 multiple immigrant-based sources of information for dispersal decisions in a ciliate. Journal of $524 \quad$ Animal Ecology 84:1373-1383. DOI: 10.1111/1365-2656.12380.

525 Jacob S, Laurent E, Haegeman B, Bertrand R, Prunier JG, Legrand D, Cote J, Chaine AS, Loreau M, Clobert

526 J, Schtickzelle N. 2018. Habitat choice meets thermal specialization: Competition with specialists 527 may drive suboptimal habitat preferences in generalists. Proceedings of the National Academy 528 of Sciences 115:11988-11993. DOI: 10.1073/pnas.1805574115.

529 Jacob S, Legrand D, Chaine AS, Bonte D, Schtickzelle N, Huet M, Clobert J. 2017. Gene flow favours local $530 \quad$ adaptation under habitat choice in ciliate microcosms. Nature Ecology \& Evolution 1:1407. DOI: $531 \quad 10.1038 / s 41559-017-0269-5$.

532 Jacob S, Wehi P, Clobert J, Legrand D, Schtickzelle N, Huet M, Chaine A. 2016. Cooperation-mediated 533 plasticity in dispersal and colonization. Evolution 70:2336-2345. DOI: 10.1111/evo.13028.

534 Kuefler D, Avgar T, Fryxell JM. 2012. Rotifer population spread in relation to food, density and predation 535 risk in an experimental system. Journal of Animal Ecology 81:323-329. DOI: 10.1111/j.1365$536 \quad$ 2656.2011.01917.x.

537 Leick V, Chen F. 2004. Chemosensory behaviour and ciliary cyclic GMP-dependent protein kinase in 538 Tetrahymena thermophila. European Journal of Protistology 40:303-312. DOI:

$539 \quad$ 10.1016/j.ejop.2004.05.006.

540 Leys C, Ley C, Klein O, Bernard P, Licata L. 2013. Detecting outliers: Do not use standard deviation 541 around the mean, use absolute deviation around the median. Journal of Experimental Social $542 \quad$ Psychology 49:764-766. DOI: 10.1016/j.jesp.2013.03.013.

543 Mancinelli G. 2010. Intraspecific, size-dependent variation in the movement behaviour of a brackish544 water isopod: A resource-free laboratory experiment. Marine and Freshwater Behaviour and Physiology 43:321-337. DOI: 10.1080/10236244.2010.512728. 
546 Menden-Deuer S. 2010. Inherent high correlation of individual motility enhances population dispersal in

547 a heterotrophic, planktonic protist. PLoS Computational Biology 6:e1000942.

548 Mitchell JG. 2002. The energetics and scaling of search strategies in bacteria. The American Naturalist

$549 \quad 160: 727-740$.

550 Morales JM, Ellner SP. 2002. Scaling up animal movements in heterogeneous landscapes: the

$551 \quad$ importance of behavior. Ecology 83:2240-2247.

552 Nathan R, Getz WM, Revilla E, Holyoak M, Kadmon R, Saltz D, Smouse PE. 2008. A movement ecology

553 paradigm for unifying organismal movement research. Proceedings of the National Academy of

554 Sciences 105:19052-19059. DOI: 10.1073/pnas.0800375105.

555 Newlands NK, Lutcavage ME, Pitcher TJ. 2004. Analysis of foraging movements of Atlantic bluefin tuna

556 (Thunnus thynnus): individuals switch between two modes of search behaviour. Population

557 Ecology 46:39-53. DOI: 10.1007/s10144-004-0169-9.

558 Niitepõld K, Smith AD, Osborne JL, Reynolds DR, Carreck NL, Martin AP, Marden JH, Ovaskainen O,

559 Hanski I. 2009. Flight metabolic rate and PGI genotype influence butterfly dispersal rate in the

$560 \quad$ field. Ecology 90:2223-2232. DOI: 10.2307/25592738.

561 O'Riain MJ, Jarvis JUM, Faulkes CG. 1996. A dispersive morph in the naked mole-rat. Nature 380:619-

562

621. DOI: 10.1038/380619a0.

563

564

565

566

567

568
Osborne KA, Robichon A, Burgess E, Butland S, Shaw RA, Coulthard A, Pereira HS, Greenspan RJ, Sokolowski MB. 1997. Natural behavior polymorphism due to a cGMP-dependent protein kinase of Drosophila. Science 277:834-836.

Pennekamp F. 2014. Swimming with ciliates: dispersal and movement ecology of Tetrahymena thermophila, PhD thesis. Dissertation Thesis. Louvain-la-Neuve, Belgium: Université catholique de Louvain. 
569 Pennekamp F, Mitchell KA, Chaine A, Schtickzelle N. 2014. Dispersal propensity in Tetrahymena

570 thermophila ciliates-a reaction norm perspective. Evolution 68:2319-2330. DOI:

$571 \quad 10.1111 /$ evo.12428.

572 Pennekamp F, Schtickzelle N. 2013. Implementing image analysis in laboratory-based experimental

573 systems for ecology and evolution: a hands-on guide. Methods in Ecology and Evolution 4:483-

574 492. DOI: 10.1111/2041-210X.12036.

575 Pennekamp F, Schtickzelle N, Petchey OL. 2015. BEMOVI, software for extracting behavior and

576 morphology from videos, illustrated with analyses of microbes. Ecology and Evolution 5:2584-

577 2595. DOI: 10.1002/ece3.1529.

578 Ronce O. 2007. How does it feel to be like a rolling stone? Ten questions about dispersal evolution.

$579 \quad$ Annual Review of Ecology Evolution and Systematics 38:231-253.

580 Ronce O, Clobert J. 2012. Dispersal syndromes. In: Clobert J, Baguette M, Benton TG, Bullock JM eds.

581 Dispersal ecology and evolution. Oxford: Oxford University Press, 119-138.

582 Schneider CA, Rasband WS, Eliceiri KW. 2012. NIH Image to ImageJ: 25 years of image analysis. Nature

583 Methods 9:671-675. DOI: 10.1038/nmeth.2089.

584 Schtickzelle N, Fjerdingstad E, Chaine A, Clobert J. 2009. Cooperative social clusters are not destroyed by 585 dispersal in a ciliate. BMC Evolutionary Biology 9:251.

586 Schtickzelle N, Joiris A, Van Dyck H, Baguette M. 2007. Quantitative analysis of changes in movement 587 behaviour within and outside habitat in a specialist butterfly. BMC Evolutionary Biology 7:4.

588 Stevens VM, Trochet A, Van Dyck H, Clobert J, Baguette M. 2012. How is dispersal integrated in life 589 histories: A quantitative analysis using butterflies. Ecology Letters 15:74-86. DOI:

$590 \quad$ 10.1111/j.1461-0248.2011.01709.x.

591 Stevens VM, Turlure C, Baguette M. 2010. A meta-analysis of dispersal in butterflies. Biological Reviews 592 $85: 625-642$. 
593 Turchin P. 1998. Quantitative Analysis of Movement: Measuring and Modeling Population Redistribution $594 \quad$ in Animals and Plants. Sunderland: Sinauer Associates.

595 Turlure C, Schtickzelle N, Dyck HV, Seymoure B, Rutowski R. 2016. Flight Morphology, Compound Eye 596 Structure and Dispersal in the Bog and the Cranberry Fritillary Butterflies: An Inter- and 597 Intraspecific Comparison. PLOS ONE 11:e0158073. DOI: 10.1371/journal.pone.0158073.

598 Van Petegem KHP, Pétillon J, Renault D, Wybouw N, Leeuwen TV, Stoks R, Bonte D. 2015. Empirically 599 simulated spatial sorting points at fast epigenetic changes in dispersal behaviour. Evolutionary $600 \quad$ Ecology 29:299-310. DOI: 10.1007/s10682-015-9756-9.

601 Wheat CW. 2012. Dispersal Genetics: Emerging Insights from Fruitflies, Butterflies and Beyond. In:

602 Clobert J, Baguette M, Benton TG, Bullock JM eds. Dispersal and spatial evolutionary ecology. $60395-107$.

604 Young KD. 2007. Bacterial morphology: why have different shapes? Current Opinion in Microbiology 605 10:596-600. DOI: 16/j.mib.2007.09.009.

606 


\section{Figure 1}

Model selection for the four types of continuous time movement models fitted to 23 randomly selected trajectories.

Relative frequencies of the most parsimonious model shown for A) resident trajectories across genotypes B) disperser trajectories across genotypes. The ACVM model is the most represented, followed by the UCVM. Some trajectories are best represented by rotational variants (RACVM and RCVM).

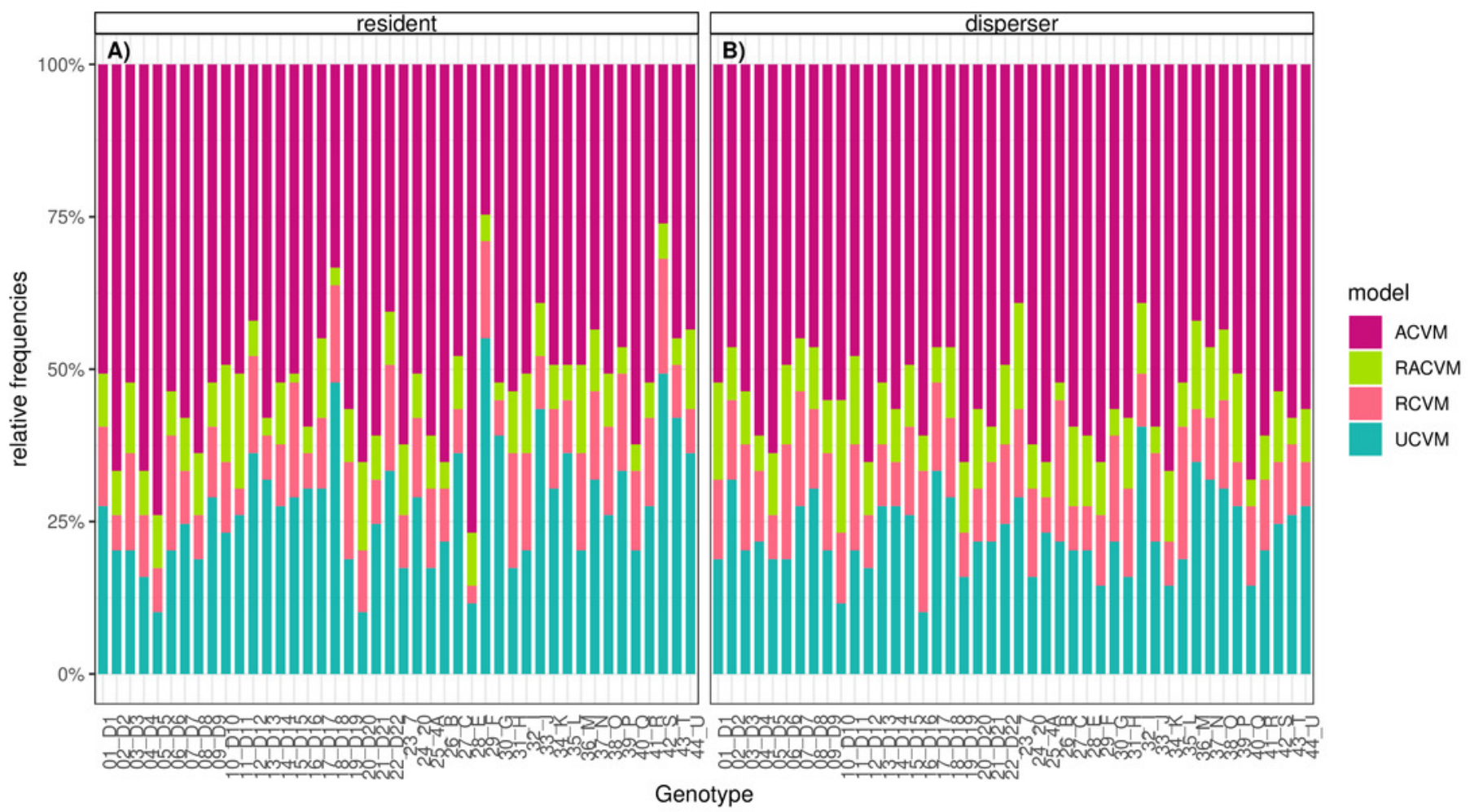


Figure 2

Overview of among and within genotype variation in A) activity, B) speed and C) tau, i.e. linearity.

Each line shows a genotype and its slope indicates differences in movement among status (disperser vs resident).

A

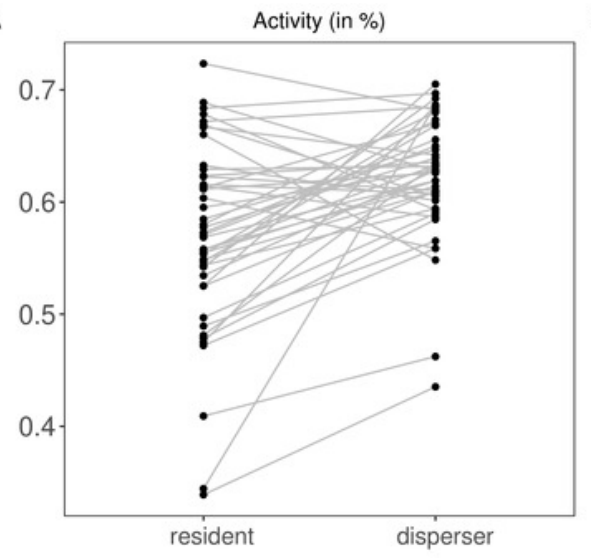

B

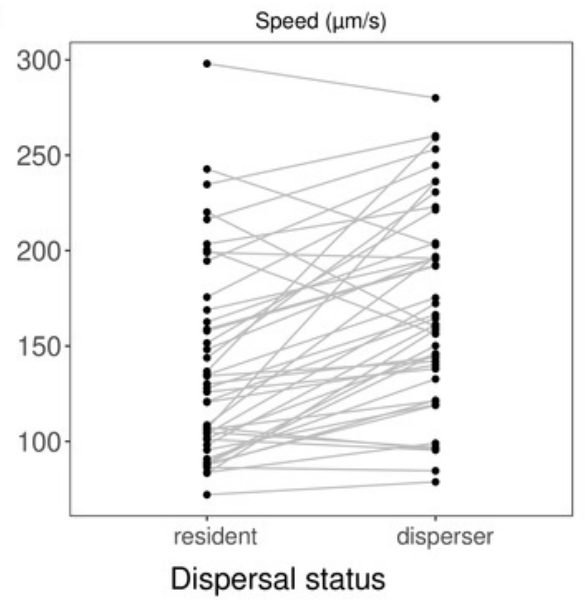

C

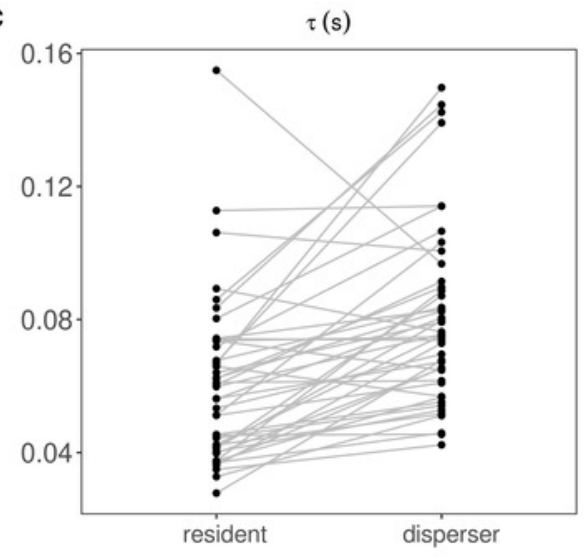




\section{Figure 3}

Relationships between speed (A, B) and tau, i.e. linearity (C, D), dispersal status (red and blue) and cell morphology (size and shape).

Lines and confidence intervals show the partial effects of size and shape of the most parsimonious ANCOVA model $(n=262)$. Larger cells moved faster but not more linear, with an overall higher level in dispersing cells. In contrast, only in dispersing cells elongation resulted in faster and straighter movement, whereas the opposite was observed in resident cells. 

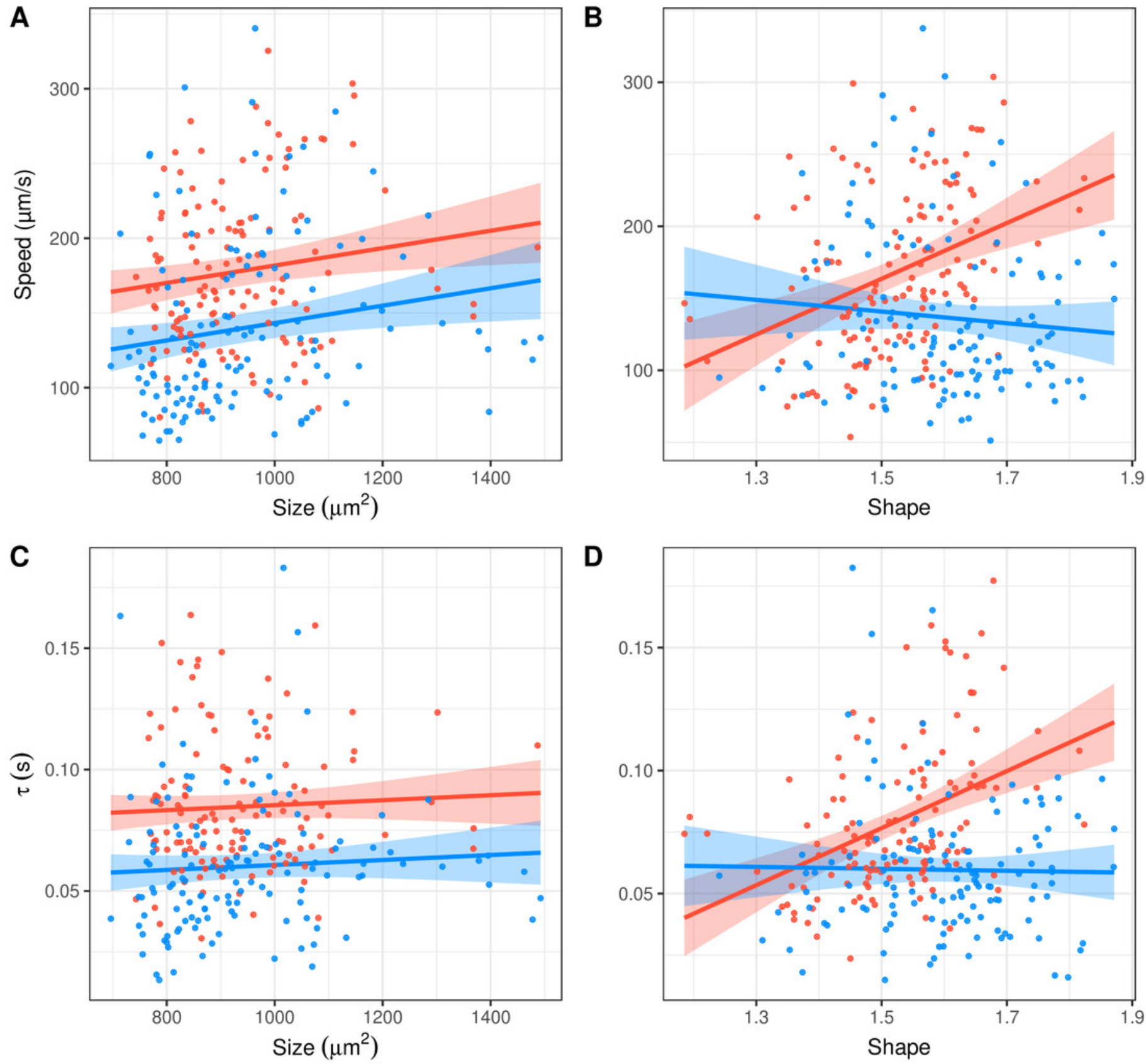

D

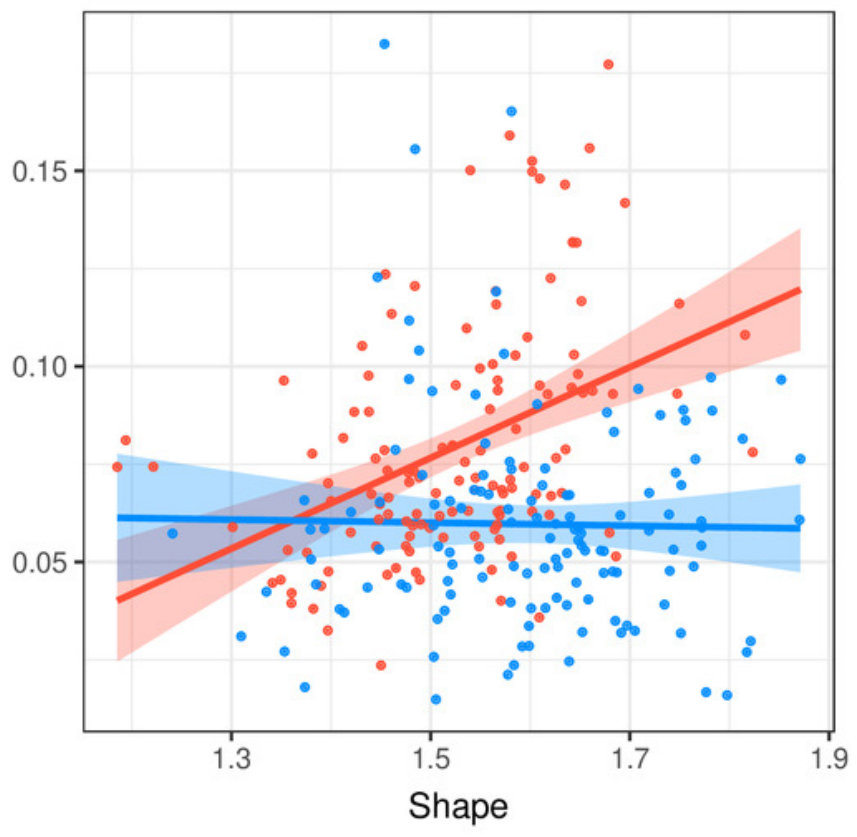

Dispersal status

disperser

resident 
Figure 4

The 44 genotypes differed in their dispersal rate in the two-patch experimental system over a period of $6 \mathrm{~h}$.

The point represents the mean dispersal and the error bars the standard error of the mean ( $n=3$ per genotype).

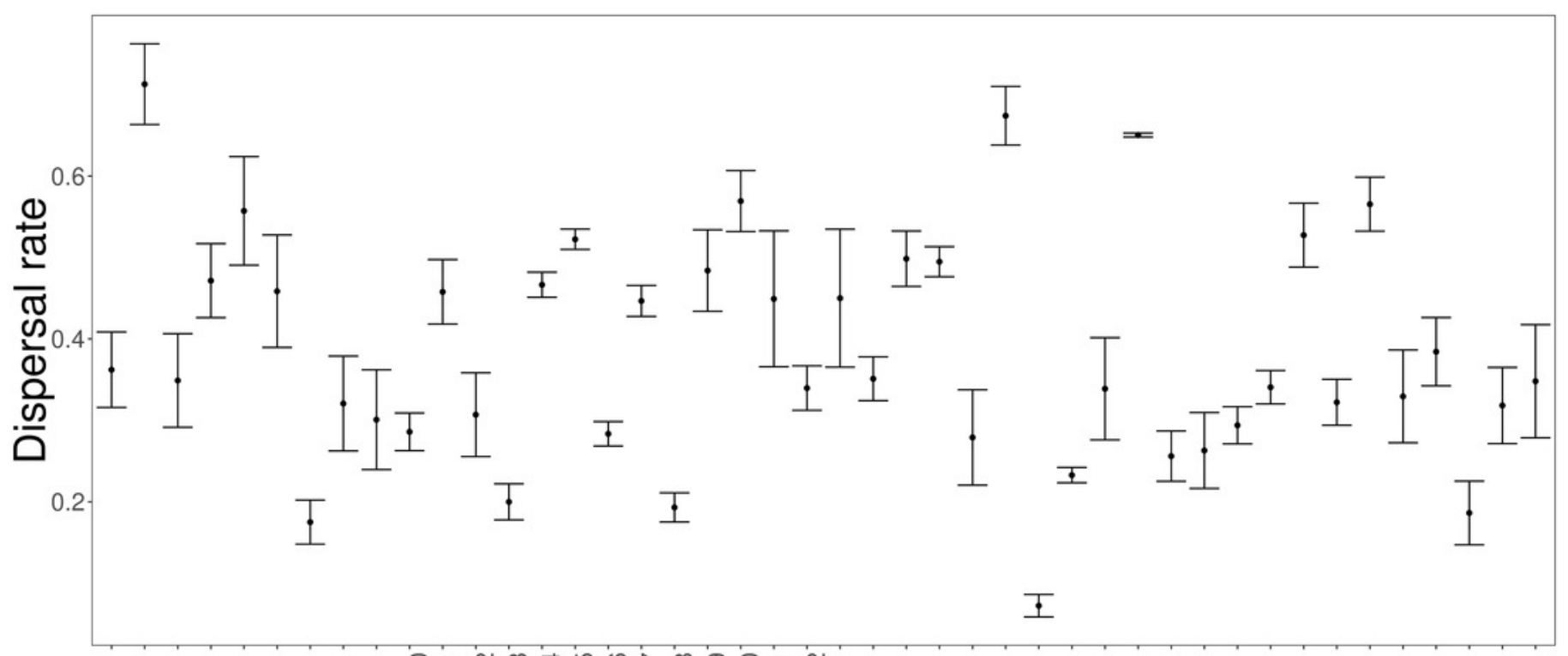

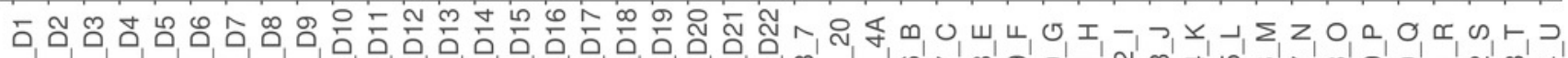

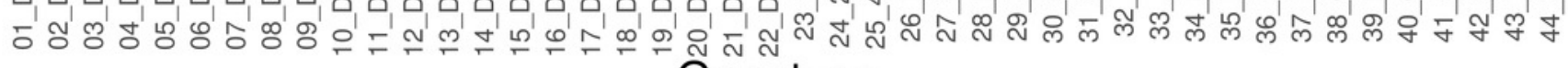
Genotype 


\section{Table $\mathbf{1}$ (on next page)}

Three-way ANOVA to assess the effect of genotype and the dispersal status (i.e. difference between dispersers and residents) on three movement metrics: activity (proportion of moving cells), movement speed and linearity.

Genotype and dispersal status were considered as crossed and fixed effects, and replicate as random effect nested in genotype but crossed with dispersal status because data from the two status were paired per replicate (i.e. the start and target tubes of one dispersal system). The column "denominator for F-test" indicates the error term used to test for each effect, according to the ANOVA model; "-" denote the factors that cannot be tested because the error has no degrees of freedom in this model. 


\begin{tabular}{|c|c|c|c|c|c|c|c|c|c|c|c|c|c|c|}
\hline \multirow{2}{*}{$\begin{array}{l}\text { Response variable } \\
\text { Factor }\end{array}$} & \multirow[b]{2}{*}{$\begin{array}{l}\text { Denominator for F- } \\
\text { test }\end{array}$} & \multirow[b]{2}{*}{ DF } & \multicolumn{4}{|c|}{ activity } & \multicolumn{4}{|c|}{ speed: $\ln ($ speed) } & \multicolumn{4}{|c|}{ linearity: $\ln (\operatorname{tau})$} \\
\hline & & & SS & MS & $\begin{array}{l}\mathrm{F} \\
\text { value }\end{array}$ & $p$ & SS & MS & F value & $p$ & SS & MS & $\begin{array}{l}\mathrm{F} \\
\text { value }\end{array}$ & $p$ \\
\hline genotype & $\begin{array}{l}\text { replicate } \\
\text { (genotype) }\end{array}$ & 43 & 0.872 & 0.020 & 2.88 & \begin{tabular}{|l|}
$<$ \\
0.0001 \\
\end{tabular} & 24.927 & 0.580 & 12.40 & $<0.0001$ & 24.666 & 0.574 & 7.50 & $<0.0001$ \\
\hline $\begin{array}{l}\text { dispersal status } \\
\text { (disperser vs } \\
\text { resident) }\end{array}$ & $\begin{array}{l}\text { replicate * } \\
\text { dispersal status } \\
\text { (genotype) }\end{array}$ & 1 & 0.186 & 0.186 & 42.88 & $\begin{array}{l}< \\
0.0001\end{array}$ & 3.193 & 3.193 & 149.28 & $<0.0001$ & 6.718 & 6.718 & 93.19 & $<0.0001$ \\
\hline $\begin{array}{l}\text { genotype * dispersal } \\
\text { status }\end{array}$ & $\begin{array}{l}\text { replicate * } \\
\text { dispersal status } \\
\text { (genotype) }\end{array}$ & 43 & 0.445 & 0.010 & 2.39 & 0.0003 & 3.977 & 0.092 & 4.32 & $<0.0001$ & 7.036 & 0.164 & 2.27 & 0.0006 \\
\hline replicate (genotype) & error & 87 & 0.612 & 0.007 & - & - & 4.067 & 0.047 & - & - & 6.653 & 0.076 & - & - \\
\hline $\begin{array}{l}\text { replicate * dispersal } \\
\text { status (genotype) }\end{array}$ & error & 87 & 0.377 & 0.004 & - & - & 1.862 & 0.021 & - & - & 6.272 & 0.072 & - & - \\
\hline error & na & 0 & 0 & - & & & 0 & - & & & 0 & - & & \\
\hline total & & 261 & 2.490 & & & & 38.020 & & & & 51.317 & & & \\
\hline
\end{tabular}

